\title{
The Status of Value Management Practice on Construction Projects in Uganda and Strategies for Improvement
}

\author{
Apollo Tutesigensi', "Nathan Kibwami² and Saul B. Matege 1,3
}

\begin{abstract}
First submission: 30 May 2020; Accepted: 29 November 2020; Published: 8 December 2021
To cite this article: Apollo Tutesigensi, Nathan Kibwami and Saul B. Matege (2021). The status of value management practice on construction projects in Uganda and strategies for improvement. Journal of Construction in Developing Countries, 26(2): 251-267. https://doi.org/10.21315/jcdc2021.26.2.12.
\end{abstract}

To link to this article: https://doi.org/10.21315/jcdc2021.26.2.12

\begin{abstract}
In many developing countries, value management (VM) is not applied widely and systematically in construction projects. This limits the achievement of value for money. The objectives of this study were to describe the state of VM practice in Uganda and suggest strategies for improvement. Based on the extant literature, a conceptual framework depicting VM practice in the lifecycle of construction projects was developed. A questionnaire containing both nominal and ordinal measures was distributed to a sample of Ugandan construction industry professionals. During data analysis, the distributions of nominal variables were expressed in terms of percentages. A univariate analysis of the ordinal variables was undertaken using measures of central tendency (mean) and dispersion (standard deviation). A bivariate analysis of the ordinal variables was undertaken using Friedman, Fisher's exact and Mann-Whitney U tests. The application of VM in Uganda was rudimentary, inconsistent and misguided, based on the reports of the respondents. This finding constitutes the first major contribution of this work to knowledge. It also led to the idea that the practice of VM in Uganda can be improved by raising awareness and the standard for VM application. Ten strategies for these two purposes have been put forward in this article. These strategies constitute the second major contribution to knowledge.
\end{abstract}

Keywords: Construction industry, Construction professionals, Uganda, Value management

\section{INTRODUCTION}

In the context of construction projects, value management (VM) optimises value throughout the project lifecycle by making the various stakeholders' differing priorities explicit and aligning them, thereby enabling the selection of optimum solutions with available resources (Institute of Valve Management, 2018; Kelly, Male and Graham, 2015). VM is associated with several benefits to construction projects, such as improvements in performance, efficiency, competitiveness, transparency, and reputation, in addition to the creation of a common value culture (Dahiru, 2019; Khodeir and El Ghandour, 2019; Fong, 2004). Hence, it is necessary to formulate strategies for increasing the level of application of VM throughout the world, particularly in developing countries, where VM has not diffused to an appreciable level.

\footnotetext{
'School of Civil Engineering, University of Leeds, LS2 9JT, Leeds, UNITED KINGDOM

${ }^{2} \mathrm{~S}$ chool of the Built Environment, Department of Construction Economics and Management, Makerere University, PO Box 7062, Kampala, UGANDA

${ }^{3}$ MBW Consulting Ltd., Plot 107 Kira Road, PO Box 8493, Kampala, UGANDA

*Corresponding author: nathan.kibwami@mak.ac.ug
} 
The application of VM in construction projects started in the 1970s in the United States of America (USA). In the last 40 years, VM has spread to Europe and Australia and become an established framework in the construction industry with common tools, techniques and styles (Kelly, Male and Graham, 2015; Spaulding, Bridge and Skitmore, 2005). Although VM is now generally widespread internationally, its application in the construction industry is still not well established in many developing countries. Outside Europe, the USA and Australia, various studies undertaken to investigate the state of the application of VM in construction projects in specific countries (including China, Hong Kong, Nigeria, South Africa and Vietnam) generally show that the application of VM in construction projects is increasing, although it has been applied on a small proportion of construction projects and is often limited to the design and construction stages (Khodeir and El Ghandour, 2019; Aghimien, Oke and Aigbavboa, 2018; Kim et al., 2016; Bowen et al., 2010; Liu and Shen, 2005; Fong and Shen, 2000).

A systematic search of literature about VM in Uganda revealed no publications. Therefore, Uganda is one of the developing countries where the status of the application of VM is not well documented. In general, the application of VM has been shown to improve performance within the construction industry (Madushika et al., 2020; Roslon, Ksiqziek-Nowak and Nowak, 2020; Shahhosseini, Afshar and Amiri, 2017). The lack of a discourse on VM in Uganda suggests that the potential of VM to contribute to construction industry performance is relatively untapped and therefore presents an opportunity for considerable improvement. Hence, the present research was undertaken with two objectives: (1) To describe the current status of VM practice in Uganda and (2) To propose strategies that will help realise improvement in VM practice in Uganda.

\section{OVERVIEW OF VM THEORY AND PRACTICE}

VM concerns maximising value. Value is defined as the relationship between the satisfaction of needs (benefits) and resources used in achieving that satisfaction (costs). In other words, VM is concerned with harmonising the relationship between benefits and costs (Institute of Value Management, 2018; British Standards Institute, 2000). VM is therefore aimed at making explicit the various stakeholders' differing priorities, needs and expectations and then aligning them; this enables the achievement of an acceptable balance with required resources (Institute of Value Management, 2018).

At the project level, VM can be defined as a systematic, multi-disciplinary effort directed towards analysing the functions of projects for the purpose of achieving the best value at the lowest overall lifecycle cost (Norton and McElligott, 1995). Therefore, VM (at the project level) covers a full range of available methods and tools and all specific forms of its application. At its best, VM maximises the functional value of a project as it is developed from a concept through operation and thus increases the value for money incurred over the project lifecycle (Kelly, Male and Graham, 2015).

The conceptualisation of VM in construction projects is usually based on a typical project lifecycle that includes pre-briefing, briefing, conceptual design, detailed design, construction and operation (Bowen, Edward and Cattell, 2009). Based on these project phases, the exploration of the extant VM literature 
suggests three themes that are ubiquitously discussed by scholars: forms of $V M$, methods of VM and tools of VM. The forms of VM include value planning, value engineering, values analysis and value review (Uganda Road Fund, 2018; Luvara and Mwemezi, 2017; Kelly, Male and Graham, 2015; Jaapar, Maznan and Zawawi, 2012; Sievert, 1991). The methods of VM widely discussed in the literature include an orientation meeting, contractor's change, value for money audit, 40hour workshop, shortened study, charrette and concurrent study (Uganda Road Fund, 2018; Office of the Auditor General, 2017a; Shen and Yu, 2015; Perera, Hayles and Kerlin, 2011; Male et al., 1998; Kelly and Male, 1993). In addition, the tools of VM include function analysis, function cost, function performance specification, function analysis system technique (FAST), simple multi-attribute rating technique (SMART), lifecycle/whole life costing and spatial adjacency analysis (Kelly, Male and Graham, 2015; SAVE International, 2015; Bowen, Edward and Cattell, 2009; British Standards Institute, 2000; Cheah and Ting, 2005; Younker, 2003; Green, 1994).

By mapping forms of VM, methods of VM and tools of VM over the typical project lifecycle phases, a conceptual framework was generated, as summarised in Figure 1. The conceptual model is premised on the idea that, ideally, VM methods and tools should be applied in their respective phases of all projects. This conceptual framework was used to design research instruments to enable data collection.

\section{VM IN UGANDA}

A systematic search was undertaken for all literature about VM in Uganda up to and including December 2019. The only reference to VM research in Uganda found was a 2010 unpublished postgraduate dissertation by David Kivumbi, entitled "Adaptation of the Smart Methodology to Valve Management of the Uganda School Facilities Grant". The paucity of VM research in Uganda is likely to be an indication of the limited and unsystematic application of VM in Uganda's construction industry.

In terms of VM practice, there is evidence of some (but very limited) effort to address VM in the public sector. In order to improve the value for money in public sector projects, the 1995 Constitution of Uganda, specifically, Article 163(3)(b), concerning the Auditor General, and the National Audit Act of 2008, mandate that all projects involving public funds can be subjected to value for money (VFM) audits to check whether principles of economy, efficiency and effectiveness have been followed and whether there is room for improvement. In accordance with these regulations, Uganda's Office of the Auditor General regularly undertakes VFM audits on a variety of government projects, including construction projects, every year (Office of the Auditor General, 2017b). These VFM audits tend to be forensic audits carried out after a project is completed. Therefore, from a project lifecycle perspective, such VFM audits happen only in the operation phase (Office of the Auditor General, 2020). Hence, the VFM audits cannot lead to improvements or maximisation of $V M$ in the specific projects in question. In addition, the VFM audits are not undertaken on all public sector projects and as far as private sector projects are concerned, there is no evidence of formal VM practice. 
Apollo Tutesigensi, Nathan Kibwami and Saul B. Matege

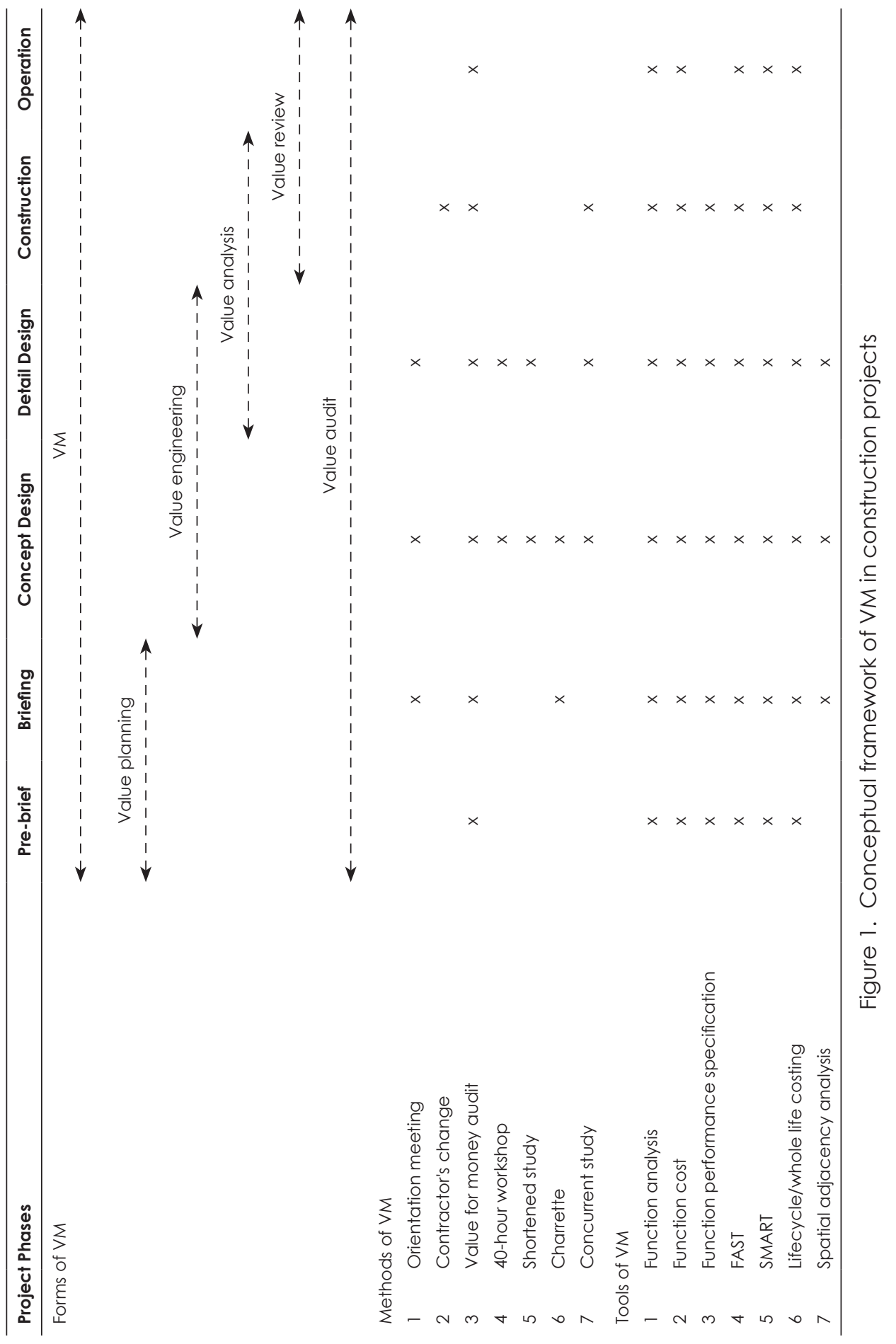


From the foregoing, it can be concluded that VM has not diffused in Uganda's construction industry. Because the literature (e.g., Madushika et al., 2020; Roslon, Książek-Nowak and Nowak, 2020; Shahhosseini, Afshar and Amiri, 2017) has shown that the application of VM can improve performance within the construction industry, the lack of VM practice suggests that the industry is operating at a lower level of performance and development than necessary. Popularising VM is worth the effort since through regulations, Uganda has already committed to value for money in its projects at the highest levels, and VM will lead to a wider and timely realisation of the intentions of the regulations. Therefore, levels of performance and the development of Uganda's construction industry can be improved by a concerted effort to facilitate the systematic application of VM. However, such an effort should be based on understanding the baseline state of VM practice. The research reported in this article was undertaken to provide such a baseline and suggest strategies to facilitate the systematic application of VM in Uganda.

\section{METHODS}

The population of reference was construction industry professionals in Uganda, including architects, engineers and quantity surveyors. Contact information was available from official lists of registered professionals for the year 2017, as published by the respective professional regulatory bodies. A random sample of 328 professionals (comprised of 87 architects, 192 engineers and 49 quantity surveyors) was drawn. In order to collect primary data, a questionnaire was designed using an online survey provider (onlinesurveys.ac.uk) and made available to the respondents by an email solicitation and link.

Because the absence of literature, as highlighted in the two previous sections, suggested that the level of maturity of VM practice was low, the issues being researched were envisaged as possibly being unfamiliar to some respondents. As such, show cards (Singh, 2007), containing relevant definitions and illustrations of the VM concept, project lifecycle, methods of VM and tools of VM, were embedded in the questionnaire. Table 1 provides a summary of the study variables and how they were measured in the questionnaire.

A number of statistical tests, including Fisher's exact test, Friedman test and Mann-Whitney U test (Gray and Kinnear, 2012), were used to address the research objective of describing the current status of VM practice in Uganda. The various assumptions underlying each of the statistical tests, such as homogeneity of variance, were examined before applying the appropriate statistical tests (Fielding, Lee and Blank, 2016). 
Table 1. Variables, their measurement and measurement scales

\begin{tabular}{|c|c|c|}
\hline Variable & Measurement/Question & Measurement Scale \\
\hline \multirow[t]{2}{*}{ Profession } & \multirow{2}{*}{$\begin{array}{l}\text { Which of the following describes } \\
\text { your profession? }\end{array}$} & Nominal scale: \\
\hline & & $\begin{array}{l}\text { Architect; Civil engineer; } \\
\text { Electrical engineer; } \\
\text { Mechanical engineer; } \\
\text { Quantity surveyor; Other }\end{array}$ \\
\hline \multirow{2}{*}{$\begin{array}{l}\text { Type of } \\
\text { organisation }\end{array}$} & \multirow{2}{*}{$\begin{array}{l}\text { Which of the following describes } \\
\text { your organisation? }\end{array}$} & Nominal scale: \\
\hline & & Client; Consultant; Contractor \\
\hline \multirow{2}{*}{$\begin{array}{l}\text { Professional } \\
\text { experience }\end{array}$} & \multirow{2}{*}{$\begin{array}{l}\text { How long have you been working } \\
\text { in the construction industry? }\end{array}$} & Ordinal scale: \\
\hline & & $\begin{array}{l}<5 \text { years; } 5 \text { years to } 10 \text { years; } \\
10 \text { years to } 15 \text { years; } 15 \text { years } \\
\text { to } 20 \text { years; Over } 20 \text { years }\end{array}$ \\
\hline \multirow{2}{*}{$\begin{array}{l}\text { Presence of VM } \\
\text { policy/programme }\end{array}$} & \multirow{2}{*}{$\begin{array}{l}\text { Does your organisation have } \\
\text { a VM policy or programme? }\end{array}$} & Nominal scale: \\
\hline & & Yes; No \\
\hline \multirow[t]{2}{*}{ Familiarity with VM } & \multirow[t]{2}{*}{ Are you familiar with VM? } & Nominal scale: \\
\hline & & Yes; No \\
\hline \multirow{2}{*}{$\begin{array}{l}\text { Understanding } \\
\text { of VM }\end{array}$} & \multirow{2}{*}{$\begin{array}{l}\text { By your own understanding, which } \\
\text { one of the following statements } \\
\text { best defines VM? }\end{array}$} & Nominal scale: \\
\hline & & $\begin{array}{l}\text { Increasing the benefits at } \\
\text { the same or lower cost; } \\
\text { Providing the same benefits } \\
\text { at a reduced cost; Greatly } \\
\text { increasing the benefits at a } \\
\text { slight increase in cost; All the } \\
\text { above }\end{array}$ \\
\hline \multirow{4}{*}{$\begin{array}{l}\text { Source of VM } \\
\text { knowledge }\end{array}$} & \multirow{2}{*}{$\begin{array}{l}\text { Which of the following best } \\
\text { describes how you acquired } \\
\text { knowledge about VM? }\end{array}$} & Nominal scale: \\
\hline & & $\begin{array}{l}\text { Programme of study (please } \\
\text { specify); My organisation's } \\
\text { practices; Professional } \\
\text { association; Fellow } \\
\text { professionals }\end{array}$ \\
\hline & \multirow{2}{*}{$\begin{array}{l}\text { Please specify the programme of } \\
\text { study from which you acquired } \\
\text { knowledge about VM. }\end{array}$} & Nominal scale: \\
\hline & & $\begin{array}{l}\text { Undergraduate study } \\
\text { programme; Master's study } \\
\text { programme; VM short course; } \\
\text { Other }\end{array}$ \\
\hline
\end{tabular}

(Continued on next page) 
Table 1. Continued

\begin{tabular}{|c|c|c|}
\hline Variable & Measurement/Question & Measurement Scale \\
\hline \multirow{4}{*}{$\begin{array}{l}\text { Reference to } \\
\text { established VM } \\
\text { benchmark/ } \\
\text { standard }\end{array}$} & \multirow{2}{*}{$\begin{array}{l}\text { Do you undertake VM by referring } \\
\text { to any established standard or } \\
\text { manual? }\end{array}$} & Nominal scale: \\
\hline & & Yes; No \\
\hline & \multirow{2}{*}{$\begin{array}{l}\text { Please specify the established } \\
\text { standard or manual of VM you } \\
\text { use for reference in your work. }\end{array}$} & Nominal scale: \\
\hline & & $\begin{array}{l}\text { SAVE International Value } \\
\text { Standard; British/European } \\
\text { Value Management } \\
\text { Standard; ICE Creating Value } \\
\text { from Engineering; Australian } \\
\text { Value Standard AS 4183:2007; } \\
\text { The Value Management } \\
\text { Benchmark by Male } \\
\text { et al. (1998); Others }\end{array}$ \\
\hline \multirow[t]{2}{*}{ VM methods usage } & \multirow[b]{2}{*}{$\begin{array}{l}\text { Indicate according to your own } \\
\text { actual experience over the last } \\
\text { five years, how often the following } \\
\text { (VM methods in the conceptual } \\
\text { model) were used in respective } \\
\text { stages of the lifecycles of projects } \\
\text { in which you were involved. }\end{array}$} & Ordinal scale: \\
\hline & & $\begin{array}{l}\text { Never (0); Rarely (1); Fairly } \\
\text { often (2); Very often (3); } \\
\text { Always (4) }\end{array}$ \\
\hline \multirow[t]{2}{*}{ VM tools usage } & \multirow[b]{2}{*}{$\begin{array}{l}\text { Indicate according to your own } \\
\text { actual experience over the last } \\
\text { five years, how often the following } \\
\text { (VM tools in the conceptual model) } \\
\text { were used in respective stages of } \\
\text { lifecycles of projects in which you } \\
\text { were involved. }\end{array}$} & Ordinal scale: \\
\hline & & $\begin{array}{l}\text { Never (0); Rarely (1); Fairly } \\
\text { often (2); Very often (3); } \\
\text { Always (4) }\end{array}$ \\
\hline
\end{tabular}

Univariate data analysis was undertaken in order to illuminate the status of VM practice by highlighting parameters of the distributions of the relevant variables. An appropriate measure of effect size for each statistical test was calculated, and categorisations were made in accordance with Cohen (1988). Owing to the relatively small sample size, wherever possible, exact significance values were used instead of less accurate asymptotic estimations, as recommended by Gray and Kinnear (2012). In addition, a bivariate analysis of the data was also undertaken in order to explore relationships between each pair of groups of cases formed based on the key criteria of organisation type, VM policy/programme and professional experience. This helped further illuminate the status of VM practice through exploration of differences (if any) among the different groups of cases. As with the univariate analysis, categorisations of effect size were also made in accordance with Cohen (1988), and wherever possible, exact significances were used as recommended by Gray and Kinnear (2012). 


\section{RESULTS AND DISCUSSION}

\section{Overview of Responses}

A total of 38 respondents participated in the online questionnaire survey, out of 328 identified for the target sample that had received the solicitation, giving an overall response rate of $11.6 \%$. This was not very surprising since the literature suggests that response rates for online surveys are notoriously low. Previous published studies on VM by Bowen, Edward and Cattell (2009) and Fong and Shen (2000) had similar response rates of $13.5 \%$ and $7 \%$ for their online questionnaires, respectively.

The respondents included five architects, six quantity surveyors and 27 engineers; therefore, all the key professional groups involved in Uganda's construction industry were represented. Respondents working with client (13) and consultant (25) organisations were represented. The respondents had a wide range of professional experience in terms of years of practice: None had less than five years, four had 5 years to 10 years, 11 had 10 years to 15 years, nine had 15 years to 20 years and 14 had 20 or more years of experience.

\section{State of VM Practice in Uganda's Construction Industry}

\section{Familiarity with and understanding of VM}

An overwhelming majority of the respondents (33, or $86.8 \%$ ) indicated they were familiar with VM. However, the respondents made the following selections regarding how they understood VM: 11 chose "Increasing benefits at the same or lower cost only" (Option A), four chose "Achieving same benefits at a reduced cost" (Option B), one chose "Greatly increasing benefits at a slight increase in cost" (Option C) and 17 chose "All the above" (Option D). Since Option D was the most complete description of $\mathrm{VM}$, this finding casts doubt on the suggestion that there is a high level of familiarity with VM among construction professionals in Uganda.

No association was found between type of organisation (client vs consultant) and familiarity with VM (Fisher's exact test, Exact $p=1.00$, twotailed) or between type of organisation with description of VM (Fisher's exact test, Exact $p=0.50$, two-tailed). No association was found between VM policy/ programme and familiarity with VM (Fisher's exact test, Exact $p=0.37$, two-tailed) or between VM policy/programme and description of VM (Fisher's exact test, Exact $p=1.00$, two-tailed). Furthermore, Fisher's exact test showed no association between professional experience and familiarity with VM (Exact $p=0.37$, twotailed) or between professional experience and description of VM (Exact $p=0.50$, two-tailed).

\section{Sources of VM knowledge and presence of a VM policy/programme}

A total of 33 respondents claimed to be familiar with VM, and the sources of their VM knowledge were an organisation's practices (17), fellow professionals (8), professional association (7), postgraduate studies (6), undergraduate studies (3), VM short course (3) and others (one each noted the Internet and on-the-job experience). However, it was found that $73.3 \%$ of the respondents 
whose organisation had a VM policy/programme identified the organisation's practice as a source of knowledge compared to $33.3 \%$ of respondents whose organisation did not have a VM policy/programme.

\section{Established VM standard/benchmark}

Only $21.2 \%$ of the respondents had undertaken VM using an established standard/benchmark. Of the few respondents that referred to a VM standard/ benchmark, the majority (57.1\%) reported using BS EN 12973: 2000 Value Management (British Standards Institute, 2000), 14.3\% reported using Creating Value from Engineering: ICE Design and Practice Guide (Institution of Civil Engineers, 2015), another $14.3 \%$ reported using the Value Management Benchmark (Male et al. 1998) and $28.6 \%$ reported using their organisation's quality manual and FIDIC's (International Federation of Consulting Engineers [Fédération Internationale Des Ingénieurs - Conseils]) conditions of contract. Interestingly, no respondent reported using the SAVE International Value Methodology Standard (SAVE International, 2015) or the Australian Value Standard AS 4183:2007 (Standards Australia, 2007). Therefore, there was very little reference to VM standards/benchmarks in Uganda's construction industry.

\section{VM methods usage}

The usage of VM methods in the different phases of the project lifecycle over the past five years is presented in Table 2.

Table 2. VM method usage across phases of the project lifecycle

\begin{tabular}{|c|c|c|c|c|c|c|c|c|c|c|c|c|}
\hline \multirow[t]{2}{*}{ VM Method } & \multicolumn{2}{|c|}{ Pre-Brief* } & \multicolumn{2}{|c|}{ Briefing* } & \multicolumn{2}{|c|}{$\begin{array}{l}\text { Concept } \\
\text { Design }\end{array}$} & \multicolumn{2}{|c|}{$\begin{array}{l}\text { Detail } \\
\text { Design* }\end{array}$} & \multicolumn{2}{|c|}{ Construction* } & \multicolumn{2}{|c|}{$\begin{array}{l}\text { Operation and } \\
\text { Maintenance }\end{array}$} \\
\hline & $M$ & SD & $M$ & SD & $M$ & SD & $M$ & SD & $M$ & SD & $M$ & SD \\
\hline Orientation meeting & 3 & 1.4 & 3 & 1.2 & 3 & 1.2 & 3 & 1.3 & 3 & 1.3 & 2 & 1.3 \\
\hline $\begin{array}{l}\text { Contractor's change } \\
\text { proposal }\end{array}$ & 1 & 1.4 & 2 & 1.3 & 2 & 1.3 & 2 & 1.3 & 3 & 1.1 & 2 & 1.3 \\
\hline $\begin{array}{l}\text { Value for money } \\
\text { audit }\end{array}$ & 1 & 1.3 & 1 & 1.4 & 2 & 1.4 & 2 & 1.3 & 3 & 1.2 & 2 & 1.3 \\
\hline 40-hour workshop & - & 0.7 & 1 & 0.9 & 1 & 1.1 & 1 & 1.2 & 1 & 1.2 & 1 & 1.0 \\
\hline Shortened study & 1 & 0.9 & 1 & 0.8 & 1 & 1.0 & 1 & 1.1 & 1 & 1.3 & 1 & 0.9 \\
\hline Charette method & 1 & 1.1 & 1 & 1.3 & 1 & 1.4 & 2 & 1.4 & 1 & 1.3 & 1 & 1.1 \\
\hline Concurrent study & 1 & 1.3 & 1 & 1.3 & 1 & 1.5 & 2 & 1.5 & 2 & 1.4 & 1 & 1.2 \\
\hline
\end{tabular}

"Notes: 0 = Never; 1 = Rarely; 2 = Fairly often; $3=$ Very often; $4=$ Always; $M=$ Mean and SD = Standard deviation.

The Friedman test indicated that there were significant differences in the means for the usage of VM methods for the different project phases $(p<0.05)$. The effect sizes, as measured using the coefficient of concordance $(w)$ varied among the different VM methods and manifested in the three defined categories of "Small", "Medium" and "Large". The differences were further explored with pairwise comparisons for the respective project phases for each VM method 
using a Bonferroni-adjusted Wilcoxon signed-ranks test (with effect sizes measured using matched-pair rank bi-serial correlations, $\left.r_{r b}\right)$. It was established that each VM method had some instances of statistically significant differences with effect sizes of "medium" or "large". From the findings, it can be concluded that the usage of VM methods was not uniform throughout the project lifecycle.

The findings considered along with the conceptual model (as shown in Figure 1) show that the VM methods were applied in project phases where they should not be and/or were not applied in phases where they should, as reported by the respondents. This suggests that the practice of VM in Uganda departs from the ideal as espoused in the contemporary body of VM knowledge and, therefore, has potential for improvement.

The Mann-Whitney $U$ test for a difference of mean ranks was used to examine VM method usage across the independent variables of organisation type and VM policy/programme. The results showed that between the organisation types that were considered (client and consultant), the frequency of usage was only statistically significantly different at the pre-brief phase for the orientation meeting method $(p=0.01)$; these levels had a Glass rank bi-serial correlation $=0.53$ and $a$ "large" effect size. Thus, client organisations $(M=3.31$, $\mathrm{SD}=1.11)$ used the orientation meeting method significantly more often than consultant organisations ( $M=2.08, S D=1.35$ ) at the pre-brief stage. This result may mean clients are more attentive to this VM method at the front end of projects than consultants because of the intrinsic interest they have (or should have) for value in their projects.

The Mann-Whitney $U$ test results indicated that usage of VM methods were dependent on the presence of a VM policy/program. Specifically, there was a significant difference in the usage of the orientation meeting, contractor's change proposal, 40-hour workshop, charrette and concurrent study methods based on the presence of a VM policy/programme in an organisation with generally a "medium" effect size. These results suggest that the presence of a VM policy/programme influences more frequent use of VM methods. This is not surprising since the purpose of such a policy is expected to be the diffusion/ implementation of VM in the project/organisation.

\section{VM tool usage}

The results regarding the respondents' VM tool usage in the different phases of the project lifecycle over the past five years are presented in Table 3. In general, the reported usage of VM tools was lower than those of VM methods, with all the tools reported as being used either "Fairly often" or "Rarely" (except for one instance of "Very often"). This suggests that VM was sometimes undertaken without making use of the well-established formal VM tools. 
Table 3. VM tool usage across phases of the project lifecycle

\begin{tabular}{|c|c|c|c|c|c|c|c|c|c|c|c|c|}
\hline \multirow{2}{*}{ VM Tool } & \multicolumn{2}{|c|}{ Pre-Brief" } & \multicolumn{2}{|c|}{ Briefing* } & \multicolumn{2}{|c|}{$\begin{array}{l}\text { Concept } \\
\text { Design }\end{array}$} & \multicolumn{2}{|c|}{$\begin{array}{l}\text { Detail } \\
\text { Design* }\end{array}$} & \multicolumn{2}{|c|}{ Construction* } & \multicolumn{2}{|c|}{$\begin{array}{l}\text { Operation and } \\
\text { Maintenance }\end{array}$} \\
\hline & $M$ & SD & $M$ & SD & $M$ & SD & $M$ & SD & $M$ & SD & $M$ & SD \\
\hline Function analysis & 2 & 1.5 & 2 & 1.5 & 2 & 1.3 & 3 & 1.2 & 2 & 1.4 & 1 & 1.1 \\
\hline Function cost & 1 & 1.2 & 1 & 1.2 & 2 & 1.4 & 2 & 1.6 & 2 & 1.6 & 1 & 1.3 \\
\hline $\begin{array}{l}\text { Functional } \\
\text { performance } \\
\text { specification }\end{array}$ & 1 & 1.3 & 1 & 1.1 & 2 & 1.3 & 2 & 1.5 & 2 & 1.6 & 1 & 1.3 \\
\hline $\begin{array}{l}\text { Functional analysis } \\
\text { system technique }\end{array}$ & 1 & 1.2 & 1 & 1.2 & 1 & 1.3 & 2 & 1.5 & 1 & 1.3 & 1 & 1.3 \\
\hline $\begin{array}{l}\text { Simple multi-attribute } \\
\text { rating technique }\end{array}$ & 1 & 0.9 & 1 & 1 & 1 & 1.1 & 1 & 1.2 & 1 & 1.2 & 1 & 1.1 \\
\hline $\begin{array}{l}\text { Lifecycle/whole life } \\
\text { costing }\end{array}$ & 1 & 1.2 & 1 & 1.3 & 2 & 1.5 & 2 & 1.5 & 2 & 1.5 & 1 & 1.5 \\
\hline $\begin{array}{l}\text { Spatial adjacency } \\
\text { analysis }\end{array}$ & 1 & 1 & 1 & 1.1 & 1 & 1.2 & 1 & 1.3 & 1 & 1.2 & 1 & 1.1 \\
\hline
\end{tabular}

"Notes: 0 = Never; 1 = Rarely; 2 = Fairly often; 3 = Very often; 4 = Always; $M=$ Mean and SD = Standard deviation.

The Friedman test indicated that there were significant differences in the means in the usage of $\mathrm{VM}$ tools for the different project phases $(p<0.05)$. The effect sizes, as measured using the coefficient of concordance (w), varied among the different VM tools and manifested in the three defined categories of "Small", "Medium" and "Large". The differences were further explored with pairwise comparisons for the respective project phases for each VM tool using a Bonferroni-adjusted Wilcoxon signed-ranks test (with effect sizes measured using matched-pair rank bi-serial correlations, $\left.r_{r b}\right)$. It was established that each of the $V M$ tools had some instances of statistically significant differences, with effect sizes of "Medium" or "Large". From the above, it can be concluded that the usage of VM tools was not uniform throughout the project lifecycle.

The above findings, considered along with the conceptual model (as shown in Figure 1), show that the VM tools were not applied in project phases where they should be. This is further evidence that the practice of VM in Uganda has the potential for improvement.

The Mann-Whitney $U$ tests found no significant difference of mean ranks when examining the level of usage of VM tools across organisation types. This can be explained by the low level of organisational sophistication in Uganda's construction industry, as observed by Muhwezi, Acai and Otim (2014). There was, however, a significant difference $(p<0.05)$ in the mean ranks of the levels of usage of VM tools when looking at the presence and absence of a VM policy/programme in an organisation (with generally, either a "Medium" or "Large" effect size). The usage of VM tools was higher when an organisation had a VM policy/programme. 


\section{Improving the Practice of VM in Uganda's Construction Industry}

The findings in the preceding sections suggest that the practice of VM in Uganda's construction industry can be strengthened by taking action on two related themes: raising awareness of VM and raising standards in the application of VM.

\section{Raising awareness of VM in Uganda}

The results suggest that the level of awareness of VM is currently inadequate given that only about half of the respondents demonstrated an accurate description of VM. Therefore, there is a need to improve the general level of awareness of $\mathrm{VM}$ through the dissemination of $\mathrm{VM}$ knowledge in all key construction organisations, both public and private, and all the different professions involved in construction. Hence, five suggestions to facilitate raising the level of awareness are proposed.

Firstly, VM standards/benchmarks should become the basis of VM practice in organisations. Because the most common source of VM knowledge was found to be the practices of organisations, there is a need to ensure that they are formulated to follow the established body of knowledge and best practice. Every organisation should refer to a VM standard/benchmark in the process of designing and implementing corporate and project policy.

Secondly, learning activities, such as VM seminars and workshops, should be promoted and delivered to all construction professionals. The seminars and workshops should be effectively organised and facilitated as a mechanism to teach relevant stakeholders about the various aspects of VM as well as to provide a platform for sharing experiences and ways of improving VM application in the particular context of Uganda's construction industry.

Thirdly, the undergraduate curricula for construction-related programmes should be redesigned to include comprehensive coverage of VM. Considering that postgraduate studies were found to be the most common source of VM knowledge in our study (yet, not everyone undertakes postgraduate studies), the undergraduate stage is the most obvious venue for ensuring that construction professionals in Uganda obtain VM knowledge as early as possible in the professional formation process.

Fourthly, there is a need to publish articles about VM in various construction industry journals, as well as general newspapers, magazines and websites, in order to reach not only construction professionals but also the general public, who are all potential stakeholders in construction projects in Uganda.

Fifthly, there is the need to establish a Ugandan chapter of an international VM association in the short term and a Ugandan VM association in the medium to long term. Such steps will promote interaction with international VM associations that can provide qualified trainers, workshop facilitators and consultants to support the development of VM practice in Uganda.

\section{Raising the standard of application of VM in Uganda}

The results show that the standard of application of VM is rudimentary and, in some areas, inconsistent and misguided. To address this, five suggestions are put forward. 
Firstly, it is necessary to encourage the use of an established standard/ benchmark when undertaking VM to help ensure it is undertaken correctly and uniformly across projects. This will also make the VM process easier, help guarantee effectiveness and prevent misconceptions and misguided implementation.

Secondly, a repository of various demonstration projects should be established, as was done in the United Kingdom (Office of Government Commerce, 2007). This would entail comprehensive documentation of information about demonstration projects in which VM was properly undertaken and the results tracked to show successes and failures, thus highlighting lessons from which project teams in the future can learn (Cheah and Ting, 2005).

Thirdly, there is a need to alter existing procurement practices in various ways to facilitate the effective implementation of VM. This can be achieved by promoting procurement systems that involve contractors and/or operators earlier in a project (as in design-build and build-operate-transfer) in order to get their input in VM (Fong and Shen, 2000); procurement strategies can also be used that encourage collaboration, such as framework agreements, which facilitate contractors' and design teams' involvement in not only value engineering at the design and construction phases but in continuous VM throughout the project lifecycle (Cooper and Potts, 2009). It can also be achieved by using contract forms that include provisions for the sharing of savings gained from value engineering with the contractor, such as those suggested by FIDIC (2010), or amending standard contract forms in order to encourage contractors to submit VM proposals, as is the case in the United Kingdom (Cooper and Potts, 2009). Furthermore, it can be achieved by including VM among the assessment criteria in tendering processes for both consultants and contractors.

Fourthly, it would be beneficial to create a value culture from the highest to the lowest levels of the governance structure or private corporate structure (see Cheah and Ting, 2005; British Standards Institute, 2000). The established value culture could then be used to ensure that organisations always select projects based on whether they fit into the organisation's value strategies, which should be in line with the sector value strategies; those strategies, in turn, should be in line with the national strategy/vision at the macro level. This would facilitate a top-down approach to value addition in the economy at large (British Standards Institute, 2000).

Fifthly, there is a need to establish a government VM policy/directive. This would require all relevant government departments to have VM policies and programmes. It should also make it mandatory to undertake VM on large projects, as is the case in the USA (Cheah and Ting, 2005), but with varying requirements depending on project size and scope, as was recommended by Kiboome (2017). Jaapar et al. (2012) showed that this can lead to a definite increase in interest, appreciation and implementation of VM. However, this should only be enacted after an appropriate level of VM awareness has been established to avoid the hurried labelling of wrong interventions and programmes as VM in a bid to be compliant, as was the case in China (Cheah and Ting, 2005). 


\section{CONCLUSION}

VM is a technique that has been developed and has gained international recognition over the last five decades. Many construction projects in the USA, United Kingdom and Australia have benefited from the application of VM and have achieved far better value for money. As highlighted in the first section, outside of these countries, VM research has been reported in a few developing countries: China, Nigeria, South Africa and Vietnam. This is because many developing countries (including Uganda, which is the focus of this article) have yet to embrace VM. These countries are missing out on opportunities to improve project performance and deliver better value for money. Everyone and every organisation is encouraged to embrace VM in construction projects so that they can benefit from the opportunities it has to offer. This study was undertaken with two objectives: (1) Describing the current status of VM practice in Uganda and (2) Proposing strategies to help realise improvement in VM practice in Uganda. It was based on the perspective of construction professionals who are engaged in projects for which VM is highly relevant.

The most important contribution to knowledge about the status of VM practice in Uganda is that it can be described as rudimentary and, in some areas, inconsistent and misguided. This means that the level of maturity of VM in Uganda's construction industry is very low. Given the status of VM practice in Uganda, the immediate strategies to improve its practice must focus on the two related themes of raising awareness and raising the standard of VM application. Raising awareness about VM can be accomplished with the following strategies: (1) Harmonise corporate policies with VM standards/benchmarks, (2) Deliver VM seminars and workshops for construction professionals, (3) Address VM in undergraduate curricula, (4) Produce publications about VM and (5) Create a VM association in Uganda. Raising the standard of application of VM can be accomplished with the following strategies: (1) Institutionalise VM standards/ benchmarks, (2) Establish a repository of VM demonstration projects, (3) Innovate procurement practice, (4) Promote a value culture, and (5) Promote national VM policy. These 10 strategies constitute the most important contributions to knowledge about realising improvement in VM practice in Uganda. Such improvements will put Uganda in a position to benefit from all the good things that come with the effective implementation of VM. Moreover, other countries at similar levels of VM maturity can also benefit from the suggestions presented in this study and get started on the journey of institutionalising $V M$.

\section{REFERENCES}

Aghimien, D., Oke, A. and Aigbavboa, C. (2018). Barriers to the adoption of value management in developing countries. Engineering, Construction, and Architectural Management, 25(7): 818-834. https://doi.org/10.1108/ecam -04-2017-0070.

Bowen, P., Edwards, P., Cattell, K. and Jay, I. (2010). The awareness and practice of value management by South African consulting engineers: Preliminary research survey findings. International Journal of Project Management, 28(3): 285-295. https://doi.org/10.1016/j.ijproman.2009.07.001. 
Bowen, P.A., Edwards, P.J. and Cattell, K. (2009). Value management practice in South Africa: The built environment professions compared. Construction Management and Economics, 27(11): 1039-1057. https://doi .org/10.1080/01446190903280435.

British Standards Institute (2000). BS EN 12973: 2000 Valve Management. London: British Standards Institute.

Cheah, C.Y.J. and Ting, S.K. (2005). Appraisal of value engineering in construction in Southeast Asia. International Journal of Project Management, 23(2): 151-158. https://doi.org/10.1016/j.ijproman.2004.07.008.

Cohen, J. (1988). Statistical Power Analysis for the Behavioral Sciences. Hillsdale, NJ: Lawrence Erlbaum Associates.

Cooper, A. and Potts, K. (2009). Implementing innovation through value engineering: Observations on UK civil engineering contractors. In R. McCaffer (ed.), Proceedings of Global Innovation in Construction Conference, Loughborough University, 13-16 September 2009. Loughborough, UK: Loughborough University, 84-93.

Dahiru, A. (2019). Value management concept in construction projects delivery in Kano State. Arid Zone Journal of Engineering Technology and Environment, 15(2): 355-364.

FIDIC (International Federation of Consulting Engineers) (2010). Conditions of Contract for Construction of Building and Engineering Works Designed by the Employer, Multilateral Development Bank Harmonised Edition. Geneva: FIDIC.

Fielding, N., Lee, R.M. and Blank, G. (2016). The SAGE Handbook of Online Research Methods. Thousand Oaks, CA: Sage Publications. https://doi.org/ $10.4135 / 9781473957992$.

Fong, P.S. (2004). A critical appraisal of recent advances and future directions in value management. European Journal of Engineering Education, 29(3): 377388. https://doi.org/10.1080/03043790410001663292.

Fong, P.S. and Shen, Q. (2000). Is the Hong Kong construction industry ready for value management? International Journal of Project Management, 18(5): 317-326. https://doi.org/10.1016/S0263-7863(99)00028-9.

Gray, C.D. and Kinnear, P.R. (2012). IBM SPSS Statistics 19 Made Simple. Hove, UK: Psychology Press. https://doi.org/10.4324/9780203723524.

Green, S.D. (1994). Beyond value engineering: Smart value management for building projects. International Journal of Project Management, 12(1): 49-56. https://doi.org/10.1016/0263-7863(94)90009-4.

Institute of Value Management (2018). What is value? Available at: https://ivm.org. uk/what-is-value-management [Accessed on 14 June 2019].

Institution of Civil Engineers (2015). Creating Value in Engineering: ICE Design and Practice Guide. London: Thomas Telford.

Jaapar, A., Maznan, N.A. and Zawawi, M. (2012). Implementation of value management in public projects. Procedia - Social and Behavioral Sciences, 68: 77-86. https://doi.org/10.1016/j.sbspro.2012.12.208.

Jaapar, A., Zawawi, M., Bari, N.A.A. and Ahmad, N. (2012). Value management in the Malaysian construction industry: Addressing a theory and practice gap. Procedia - Social and Behavioral Sciences, 35: 757-763. https://doi .org/10.1016/j.sbspro.2012.02.146.

Kelly, J. and Male, S. (1993). Valve Management in Design and Construction: The Economic Management of Projects. London: Taylor \& Francis. 
Kelly, J.J., Male, S. and Graham, D. (2015). Valve Management of Construction Projects. Chichester, UK: Wiley-Blackwell. https://doi.org/10.1002/978111 9007258.

Khodeir, L.M. and El Ghandour, A. (2019). Examining the role of value management in controlling cost overrun [application on residential construction projects in Egypt]. Ain Shams Engineering Journal, 10(3): 471-479. https://doi.org/ 10.1016/j.asej.2018.11.008.

Kiboome, W. (2017). Project management in developing countries: Value management as a solution to escalating construction costs in Uganda. The Engineers Journal - Uganda, 1: 40-45.

Kim, S.Y, Lee, Y., Thanh, N.V. and LUU, T.V. (2016). Barriers to applying value management in the Vietnamese construction industry. Journal of Construction in Developing Countries, 21 (2): 55-80. https://doi.org/10.21315/ jcdc2016.21.2.4.

Liv, G. and Shen, Q. (2005). Value management in China: Current state and future prospect. Management Decision, 43(4): 603-610. https://doi.org/10 $.1108 / 00251740510593585$.

Luvara, V.G. and Mwemezi, B. (2017). Obstacles against value management practice in building projects of Dar es Salaam, Tanzania. International Journal of Construction Engineering and Management, 6(1): 13-21. https://doi.org/ 10.5923/j.ijcem.20170601.02.

Madushika, W., Perera, B., Ekanayake, B. and Shen, G. (2020). Key performance indicators of value management in the Sri Lankan construction industry. International Journal of Construction Management, 20(2): 157-168. https://doi.org/10.1080/15623599.2018.1484556.

Male, S., Kelly, J., Fernie, S., Gronqvist, M. and Bowles, G. (1998). Value Management: The Valve Management Benchmark: A Good Practice Framework for Clients and Practitioners. London: Thomas Telford.

Muhwezi, L., Acai, J. and Otim, G. (2014). An assessment of the factors causing delays on building construction projects in Uganda. International Journal of Construction Engineering and Management, 3(1): 13-23. https://doi.org/ 10.5923/j.ijcem.20140301.02.

Norton, B.R. and McElligott W.C. (1995). Value Management in Construction: A Practical Guide. Basingstoke, UK: Macmillan. https://doi.org/10.1007/978-1 -349-13350-5.

Office of Government Commerce (2007). Value Management in Construction: Case Studies. London: Office of Government Commerce.

Office of the Auditor General (2020). Value for money individual audit reports. Available at: http://www.oag.go.ug/vfm-individual-audit-reports/ [Accessed on 1 November 2020]. . (2017a). Value for Money Audit Manual. Kampala: Office of the Auditor General.

(2017b). OAG Annual Performance Report 2017. Kampala: Office of the Auditor General.

Perera, S., Hayles, C.S. and Kerlin, S. (2011). An analysis of value management in practice: The case of Northern Ireland's construction industry. Journal of Financial Management of Property and Construction, 16(2): 94-110. https://doi.org/10.1108/13664381111153097. 
Roslon, J., Książek-Nowak, M. and Nowak, P. (2020). Schedules optimization with the use of value engineering and NPV maximization. Sustainability, 12(18): 7454. https://doi.org/10.3390/su12187454.

SAVE International (2015). The Value Methodology Standard. Mount Royal, NJ: SAVE International.

Shahhosseini, V., Afshar, M. and Amiri, O. (2017). Value engineering practices in infrastructure projects: A case study of llam Gas Refinery's water transmission system at Reno Mountain, Iran. International Journal of Construction Management, 18(5): 351-363. https://doi.org/10.1080/15623599 .2017 .1326298 .

Shen, Q. and Yu, A. (2015). Value Management in Construction and Real Estate: Methodology and Applications. Abingdon, UK: Routledge. https://doi.org/ $10.4324 / 9781315723297$.

Sievert, R.W. (1991). A review of value engineering as an effective system for planning building projects. Project Management Journal, 22(1): 31-38.

Singh, K. (2007). Quantitative Social Research Methods. Thousand Oaks, CA: Sage Publications. https://doi.org/10.4135/9789351507741.

Spaulding, W.M., Bridge, A. and Skitmore, M. (2005). The use of function analysis as the basis of value management in the Australian construction industry. Construction Management and Economics, 23(7): 723-731. https://doi.org/ 10.1080/01446190500040679.

Standards Australia (2007). Australian Standard: Valve Management, AS 4183:2007. Sydney: Standards Australia.

Uganda Road Fund (2018). Technical Audit Manual. Kampala: Uganda Road Fund. Younker, D.L. (2003), Valve Engineering: Analysis and Methodology: Boca Raton, FL: CRC Press. https://doi.org/10.1201/9780203912751. 